\title{
AN OVERVIEW OF THE SEAWEED CULTIVATION IN SEVERAL COUNTRIES: TECHNOLOGY AND CHALLENGE
}

\author{
Mochammad Amin Alamsjah \\ Faculty of Fisheries and Marine, Universitas Airlangga, Campus C UNAIR Jl. Mulyorejo, Surabaya, 60115 \\ Corresponding Author: alamsjah@fpk.unair.ac.id
}

\begin{abstract}
Economic development, low carbon development, green economy, millennium development goals (MDGs), blue economy and sustainable development goals (SDGs) have become a strategy to develop human resources, health, carrying capacity for the environment, income per capita, competency, skills, and to eradicate poverty. Various development strategies applied give results related to the significant development focus that has been done. Furthermore, the success of the increase in the commodity of seaweed also hangs from the direction of the economic development policy conducted by the country. Some countries apply seaweed cultivation by using biotechnology to improve the quantity and quality of the seaweed produced. However, the capacity of the processing industry in Indonesia is still not sufficient enough to be able to absorb the domestic raw materials so that the seaweed processing industry is only able to absorb $20-25 \%$ of the domestic production of Indonesia's seaweed. A strategy to increase the capacity for the cultivation and processing of seaweed can be formulated in several steps, such as the transfer of technology, incorporating technology in existing industries, business development, the attraction of foreign investment, the investigation of critical mass, and social and environment improvements.
\end{abstract}

Keywords: seaweed, cultivation, processing, strategy, development

\section{Introduction}

The economy development approach that has performed is based on several strategies, such as economic development, low carbon development, green economy, millennium development goals (MDGs), blue economy and sustainable development goals (SDGs). In general, these strategies have several aims to increase the economy level and are influenced by government policy, capital, level of public prosperity, and the competency of human resources. Economic development usually refers to the adoption of new technologies. This also includes transitioning from agriculture-based to an industrybased economy, and general improvements in living standards. O'Sullivan and Sheffrin (2003) stated that the scope of economic development includes the process and policies by which a nation improves the economic, political, and social well-being of its people. The concept of low carbon development has its roots in the UNFCCC adopted in Rio in 1992 (UNEP, 2008). In the context of this convention, low carbon development is now generally expressed using the term low-emission development strategies (LEDS - also known as low-carbon development strategies, or low-carbon growth plans). Though no formally agreed definition exists, LEDS are generally used to describe forward-looking national economic development plans or strategies that encompass lowemission and/or climate-resilient economic growth (IEA 2010). UNEP defines the green economy as: "one that results in improved human well-being and social equity, while significantly reducing environmental risks and ecological scarcities. In its simplest expression, a green economy can be thought of as one which is low carbon, resource efficient and socially inclusive". The Millennium Development Goals (MDGs) are the world's time-bound and quantified targets for addressing extreme poverty in its many dimensions: income poverty, hunger, disease, lack of adequate shelter, and exclusion-while promoting gender equality, education, and environmental sustainability. They are also basic human rights; the rights of each person on the planet to health, education, shelter, and security. MDGs has 8 goals, that is Goal 1: Eradicate Extreme Hunger and Poverty, Goal 2: Achieve Universal Primary Education, Goal 3: Promote Gender Equality and Empower Women, Goal 4: Reduce Child Mortality, Goal 5: Improve Maternal Health, Goal 6: Combat HIV/AIDS, Malaria and other diseases, Goal 7: Ensure Environmental Sustainability, and Goal 8: Develop a Global Partnership for Development. The blue economy concept has been presented subsequently in many fora and is viewed as an alternative economic model for sustainable development that puts the oceans at the centre of this approach (Lesperance, 2016). UNDP (2017) stated 
that the Sustainable Development Goals (SDGs), otherwise known as the Global Goals, are a universal call to action to end poverty, to protect the planet and to ensure that all people enjoy peace and prosperity. These seventeen goals are build on the successes of the Millennium Development Goals, while including new areas such as climate change, economic inequality, innovation, sustainable consumption, peace and justice, among other priorities. The goals are interconnected - often the key to success in one will involve tackling issues more commonly associated with another. Various development strategies applied give results related to significant developments.

The impact of development strategy with the development of seaweed

Burkart (2012) reported that a component of green economy is the economic development of low carbon, which is an economy based on biology, energy resources and renewable energy, management that is sustainable and the provision of services in accordance with regional capacity and the socioeconomic welfare interest of the community. Furthermore, the characteristics of green economy are renewable energy, green buildings, clean transportation, water management, waste management, and land management. Pauli (2010) stated that the principles of blue economy are nature's efficiency, zero waste (leaving nothing to waste, waste for one is a food for another, waste from one process is resource of energy for the other), social inclusiveness (self-sufficiency for all, social equity, more jobs, more opportunities for the poor), cyclic systems of production (endless generation to regeneration, balancing production and consumption), innovation and adaptation (the principles of the law of physics and continuous natural adaptation).

Table 1. Comparison of green and blue economy (Pauli, 2010)
\begin{tabular}{|l|l|l|}
\hline Component & $\begin{array}{l}\text { Dream of the } \\
\text { green economy }\end{array}$ & $\begin{array}{c}\text { Dream of the } \\
\text { blue economy }\end{array}$ \\
\hline \multirow{4}{*}{ What is it } & Expensive & Innovative \\
\cline { 2 - 3 } & Subsidized & Competitive \\
\cline { 2 - 3 } & $\begin{array}{l}\text { Supported by } \\
\text { taxes }\end{array}$ & Creates jobs \\
\hline Attitudes & Protect & Regenerate \\
\cline { 2 - 3 } & Comply & Change rule \\
\cline { 2 - 3 } & For and against & Choose the best \\
\hline Actions & Do less bad & Do more good \\
\hline \multirow{2}{*}{ Who } & Global & Local \\
\cline { 2 - 3 } & Corporations & Entrepreneurs \\
\hline
\end{tabular}

Furthermore, Pauli (2010) showed four sector examples of opportunity in Blue Economy Development, which are (1) ocean-based renewable energy, (2) coastal habitats and their ecosystem services (e.g. blue carbon), (3) natural products industry (e.g. seaweed, algae), (4) sustainable tourism (e.g. cultural, spiritual, ecological). In explicit terms, seaweed is expressed as a part of the natural product industry.

Indonesia is also collaborated with UNDP to implement the program of the Millennium Development Goals (MDGs) which includes (1) advocating for and monitoring Indonesia's overall progress towards the MDGs, such as combating poverty, hunger, illiteracy, disease, discrimination against women, and environmental degradation, (2) support to achieve MDGs in Papua, (3) targeted support to MDG 3 to promote gender equality and empowering women, and (4) targeted support to MDG 6 to combat HIV/AIDS, malaria and other diseases. Although not written in relation to the explicit development of seaweed, however, the programs to reduce environmental degradation are closely connected with the successful cultivation of seaweed. Similarly, efforts can be done to reduce poverty by provide jobs through the development of the cultivation of and industry of seaweed.

The United Nations (2015) reported that 2015 was set as the target year for the MDG agenda that is needed to address the three interconnected elements of sustainable development: economic growth, social inclusion and environmental sustainability. The new development agenda builds on the achievements of the MDGs, which were adopted in 2000 and have guided development action for the last 15 years. The MDGs have proven to be goal setting, and can lift millions out of poverty. The 17 new Sustainable Development Goals that apply to all can go further to end all forms of poverty to ensure no one is left behind. The new development agenda will officially be adopted by world leaders at the UN Sustainable Development Summit. More focus will be placed on the mobilisation of resources and the follow-up and review of the implementation of the goals.

The 17 Sustainable Development Goals (SDGs) and targets are "global" in nature, taking into account different national realities, capacities and levels of development and respecting national policies and priorities. The SDGS call for building peaceful, inclusive and well-governed societies with responsive institutions as the basis for shared prosperity. Fundamentally, they recognise that we cannot reach our development goals without 
addressing human rights and complex humanitarian issues at the same time. SDGs are people-centred and planet-sensitive. They are universal, applying to all countries while recognising different realities and capabilities. The goals are not independent from each other; they need to be implemented in an integrated manner. The SDGs are the result of a three year long transparent, participatory process that is inclusive of all stakeholders and people's voices. They represent an unprecedented agreement around sustainable development priorities among the 193 Member States. They have received worldwide support from civil society, businesses, parliamentarians and other actors. The decision to launch the process to develop a set of SDGs was made by the UN Member States at the United Nations Conference on Sustainable Development (Rio+20), held in Rio de Janeiro in June 2012. The goals and targets will stimulate action over the next 15 years in areas of critical importance: People, Planet, Prosperity, Peace and Partnership.

The 17 Sustainable Development Goals with 169 targets are broader in scope and will go further than the MDGs by addressing the root causes of poverty and the universal need for development that works for all people. Building on the success and momentum of the MDGs, the new global goals will cover more ground with ambitions to address inequalities, economic growth, decent jobs, cities and human settlements, industrialisation, energy, climate change, sustainable consumption and production, peace and justice. The new goals are universal and apply to all countries, whereas the MDGs were intended for action in developing countries only. A core feature of the SDGs has been the means of implementation - the mobilisation of financial resources - as well as capacity-building and the transfer of environmentally-sound technologies. The new goals recognise that tackling climate change is essential for sustainable development and poverty eradication. SDG 13 aims to promote urgent action to combat climate change and its impact.

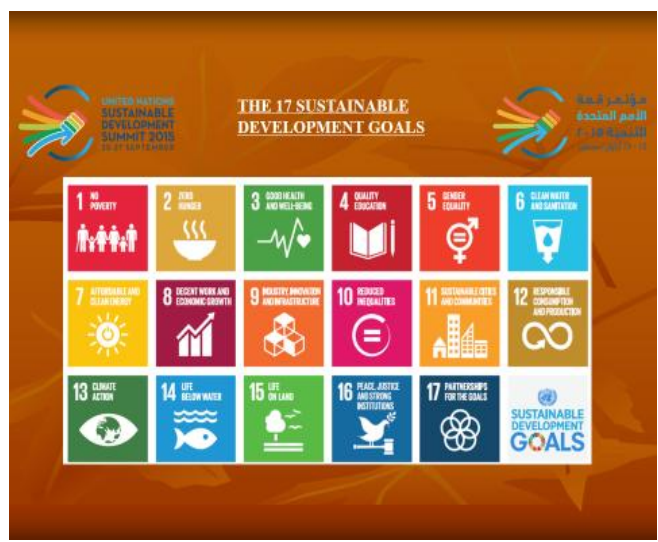

Figure 1. Sustainable development goals (UN, 2015)

At the United Nations Sustainable Development Summit, September 25-27 2015, 10 key facts were decided about the sustainable development goals (SDGs) or "global goals", which are:

1. The Global Goals need you - It's not only up to governments, but it's up to all of us to take action. Even little things can make a big impact.

2. Global Goals will change the way that the world does business - They want to transform the world economy so that it works without violating workers' rights and harming the environment.

3. The Global Goals are one for all and all for one - No goal is more important than the other, and they all complement each other.

4. The Global Goals will address climate change. Climate change is one of the most pressing issues of our time and it affects every country on every continent.

5. The Global Goals will eradicate extreme poverty. The predecessors of the Global Goals, the MDGs, have helped to cut extreme poverty by half from their establishment in 2000 until today. This is a great achievement but it is not enough! The Global Goals aim to end poverty in all its forms everywhere by 2030 .

6. The Global Goals will leave no one behind They are for young and old people, for small and big countries, for people living in rural areas and people in busy cities. They will leave no one behind.

7. The Global Goals are hands-on - They contain concrete plans about how to change 
the world, how to pay for it and how to make sure that everybody is on board.

8. The Global Goals are "Global" - They tackle challenges for all countries across the globe.

9. The Global Goals are the people's goals The goals have been developed by all of the 193 UN Member States, NGOs and people like you, all working together.

10. The Global Goals are the world's ultimate to-do list for the next 15 years - The 17 goals are for making this planet a better place by 2030 which includes ending extreme poverty, fighting inequality and fixing climate change.

Furthermore, marine bio-resources in Indonesia has showed that 2.4 million forest areas mangrove (30\% of the mangrove forests in the world are in Indonesia) and 8.5 million coral reefs (17.95\% coral reefs in the world are in Indonesia). The sustainable potential of Indonesia's marine fish resources is estimated to be 6.4 million tons / year consisting of large pelagic fish (such as tuna) 1.16 million tons, small pelagic (such as mackerel) 3.6 million tons, 1.36 million tons of demersal, penaeid shrimp 0.094 million tons, 0.004 million tons of lobster, squid 0.028 million tons, and the reef fish consumption of 0.14 million tons. The total allowable catch is 5.12 million tons / year $(80 \%$ of the sustainable potential). The potential of freshwater fishery consists of public waters (lakes, reservoirs, rivers, and swamps) covering an area of 550,000 hectares with a production of 356,020 tons / year, and a fresh water pool and rice paddy amounting to 805,700 tons / year and 233,400 tons / year. Brackish Aquaculture (ponds) reached about 913,000 Ha and there was a seaweed farming area of 2 million $\mathrm{Ha}$ ( $20 \%$ of the total potential area of marine waters within 5 miles of the coastline) with a volume of 46.73 million tons / year makes Indonesia the world's largest producer of raw seaweed.

The development of seaweed cultivation is strongly associated with environmentally-supported waters so that the accumulation of the results of seaweed cultivation is very much determined by a balanced ecosystem, the availability of organic element, the quality of the water and the application of technology to seaweed cultivation. The success of the increase in commodities of seaweed also relate to the direction of the economic development policies conducted by the country.

\section{Seaweed Cultivation}

Seaweed has been traditionally collected from natural stocks or wild populations. The amount of seaweed is declining, in part due to overharvesting. Recent advances in marine culture techniques have led to an increasing production of seaweeds as a true "marine crop". Recently, some countries apply seaweed cultivation by using biotechnology to improve the quantity and quality of the seaweed produced.

- In Japan, the cultivation methods for the most important edible seaweed (Porphyra, Monostroma, Enteromorpha, Cladosiphon, Undaria, Laminaria) are very welldeveloped. $\pm 30,000$ family cultivators (650,000 tons wet wt. annually) using the net $\left(2 \times 20 \mathrm{~m}^{2}\right.$, mesh size $\left.15 \mathrm{~cm}\right)$ and rope method. Cultivation by (1) transplanting, which can be done in the winter until spring, means that the fishermen can thin out excess fronds, complete with holdfast from the cultivation ropes and transplant them by tying them to new cultivation ropes; (2) Forced cultivation is also performed by (a) seeding done as early as possible (the end of August-middle of September), the subsequent culture of zoospore germlings in tanks; (b) regular cultivation in the sea (middle of October); (c) the cultivator needs to thin out the fronds as they grow quickly and densely on the cultivated rope (winter); (d) beginning in March, the weight and length of blades increases rapidly.

- In China, the country produces more than 1 million tons of fresh seaweeds (Laminaria, Undaria, Porphyra, Eucheuma \& Gracilaria). Seaweed cultivation is performed by (1) the Floating Raft Method through (a) setting up of the floating raft; (b) spore collection \& sporeling cultivation; (c) sporeling transplantation \& cultivation; (2) Summer Sporelings Culture Method through collect spores in summer instead of autumn, which are cultured at $6-10^{\circ} \mathrm{C}$ with a supply of nitrogen and phosphorous, and a light intensity of $60 \mu \mathrm{mol}$ photons $\mathrm{m}^{-2} \mathrm{~s}^{-1}$. After 3 months of greenhouse culture, the sporelings $(1 \mathrm{~cm})$ can be transplanted to the open sea (late autumn); (3) Fertiliser Application, in the infertile waters by using porous clay bottles, plastic bags which contained minute holes, simple spraying of fertiliser solution onto the water surface; (4) Southern Cultivation, the growth of Laminaria (5- 
$10^{\circ} \mathrm{C}$ ), however the growth is still good enough for cultivation at $13^{\circ} \mathrm{C} \&$ continued to be even at $20^{\circ} \mathrm{C}$; (5) Genetics Studies \& Breeding of New Varieties, Hybridisation for a broad, long and thick frond of Laminaria; Varieties with high iodine content and high yield, a lower water content and more rapid frond growth rate at higher temperatures; (6) Cross-breeding of different male and female gametophyte clones was developed; (7) Blade Tip Cutting Method, introduced to prevent blade decay and enhance Laminaria production in the cultivation grounds (12-15\%).

- In France, seaweed cultivation is done using the Free Living Technique through several steps, that is (a) fertile plants are collected in the field; (b) initial rough cleaning process; (c) thalli are plunged into a beaker (90 ppm $\mathrm{NaOCl}$ solution for $1 \mathrm{~min}$ ); (d) thalli are cleaned by wiping with gauze; (e) Keep overnight $\left(18^{\circ} \mathrm{C}\right)$; (f) next day, the material is immersed in sterile seawater \& mass release of spores is obtained; $(\mathrm{g})$ the solution is filtered $(30,20 \& 10 \mu)$ and poured into a flask (a sterile nutrient sol., $15-22^{\circ} \mathrm{C}$, light intensity $40 \mu \mathrm{mol}$ photons $\mathrm{m}^{-2} \mathrm{~s}^{-1}$ ); (h) the medium has to be change weekly; (i) maturation; (j) zygote can be sprayed on to polyamid line and germinate into juvenile sporophytes; (k) after 3 weeks, sporophyte plantlets $(3-5 \mathrm{~mm})$ cover the yarn; (1) transfer to the sea for on-growing (less than 50,000 tons wet wt. annually)

- In Philippines, the kind of seaweed cultivation are for Caulerpa lentillifera, Eucheuma denticulatum, E. gelatinae, E. arnoldii, Kappaphycus alvarezii, $K$. striatum, $K$. procusteanum, K. cottonii ( $\pm 40,000$ tons dry wt. annually). This is done using (1) Pond Culture through the development production consisting of several activities : (a) site selection, (b) pond construction, (c) planting, (d) management, (e) fertilization, (f) harvest and post-harvest; (2) Open Lagoon Cultivation, where bunches of Caulerpa cuttings are half buried into the muddy substratum at $0.5 \mathrm{~m}$ intervals. The process of seaweed cultivation is then done by partial harvesting.

- In Israel, seaweed cultivation uses On-Land Pond Cultivation by using an elongated pond of 1,500 $\mathrm{m}^{2}$ through (a) a paddle wheel raceway pond of $40 \mathrm{~cm}$ water depth with 2 paddles; (b) continuous seawater supply (10$20 \%$ daily rate of water exchange); (c) a weekly pulse feed of nitrogen \& phosphate; (d) $\mathrm{pH}$ control of the water by $\mathrm{CO}_{2}$ enrichment; (e) control of epiphyte competitors, grazers and disease inducing bacteria; (f) gradual harvest which keeps the seaweed density at $4-8 \mathrm{~kg} \mathrm{~m}^{-2}$ using optimal seasonal irradiance levels.

- In Indonesia, seaweed cultivation is done concentrating on Eucheuma and Gracillaria up until now, whereas Sargassum, Gelidium and Hypnea are still harvested from the wild $( \pm 30,000$ tons dry wt. annually). Seaweed farmers and technicians perform several culture systems, such as (1) the Bottom Method, whereas the seeds are dispersed at the bottom of brackish water ponds; (2) Offbottom Method, where the seed is tied on plastic rope; (3) Floating Rack Method, where the seed is tied to plastic rope and then the rope is connected to a bamboo raft; (4) Long Line Method, where the seed is tied to a plastic rope then connected to a main rope. It can be done in deep water.

Table 2. Seaweed cultivation research development

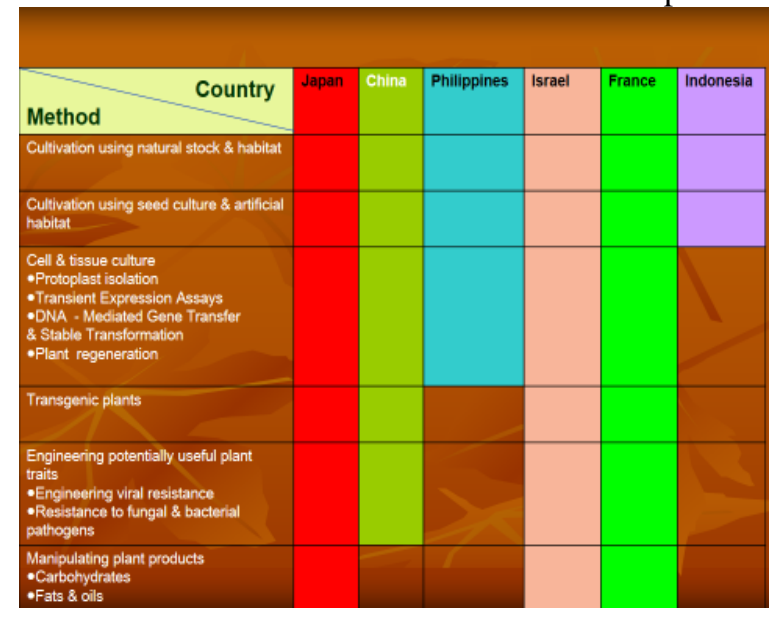

\section{Seaweed processing}

At this time, the fishery industries and the programs of the Ministry of Marine and Fisheries allows for the above to be applied in order to leverage the use of seaweed, but from the operational side, there are still many obstacles faced by Indonesia, including that Indonesia still relies on imports for refined products (agar, alginate, carrageenan). In 2011, imports reached 1,380 tons or $70 \%$ of the total demand and Indonesia also imported 800 tons of agar flour. The capacity of the processing 
industry is still not sufficient enough to be able to absorb domestic raw materials so that the seaweed processing industry is only able to absorb $20-25 \%$ of the results of the domestic production of seaweed (P2HP, 2013).

Indonesian seaweed production was targeted to be 10 million tons in 2014. Indonesian seaweed farmer's results cannot all be absorbed by the companies due to several factors, including the quality of kelp (seaweed seedlings problems, moisture content, gel strength, gelling point, and melting point). The program's central grouping (cluster) of seaweed cultivation and the industrialisation of seaweed has been conducted by the Ministry of Maritime Affairs and Fisheries as in East Java, NTB, NTT, South Sulawesi and North Sulawesi. However, the number of units of the Indonesian seaweed processing industry is only 28 units spread across 13 provinces, with the manufacturer's specifications of refined carrageenan being 25 units and 3 units. Until 2014, Indonesia's seaweed production still largely dwelled on the stages of raw material supply and the relative few who started production (agar, carrageenan) and have not been able to independently move towards the industrialisation of the final product (pharmacy, food, industrial grades).

The last review mentioned that seaweed has more than 500 applications for "end products" as well as having more economical use than just gelatin and gum as other additives. This means that the use of seaweed is very broad and has become an integral part of the food and non-food industries, either as a direct food or other product support as emulsifiers, thickeners, and purifiers. The comparison of the prices of raw material seaweed products compared to the production of materials (agar, alginate, and carrageenan) and the final product with the use of biotechnology (pharmaceuticals, cosmetics, food supplements) is 1: 10: 100 .

Seaweed harvesting time which is not in accordance with the needs of importers and seaweed selling price is considered to be too low by seaweed farmers also became an obstacle. The continuity of product supply, global financial dynamics, and the specification of refined products that do not meet business requirements and cause competition between seaweed processing companies from Indonesia and abroad in the collecting of raw materials.
Table 3. World seaweed exporters (ITC, modified 2006)

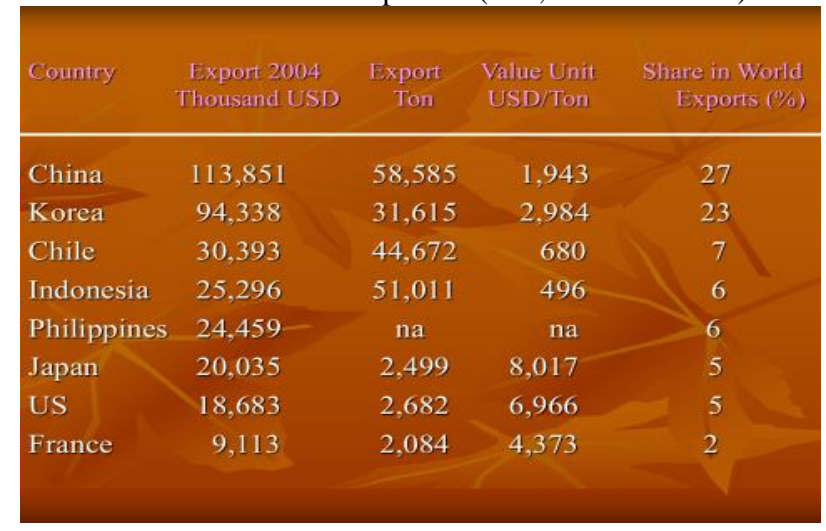

A strategy to increase the capacity for the cultivation and processing of seaweed can formulated in several steps:

\section{(1) Transfer of technology}

There is a need to accelerate scientific dissemination and marine biotechnology at every stage of production as well as in relation to apply the research done by domestic stakeholders (industry seaweed, seaweed farmers, Institute for Research / Research Implementation Unit under the coordination of the Department of Fisheries and Marine Resources and Education high) in order to produce a variety of products. In addition to this,, there are public conferences and training intensely so that the application of marine biotechnology can become one of the standard procedures seaweed breeding technology leading to the technological diversification of processed seaweed products.

\section{(2) Incorporate technology in existing industries}

There is the need to study the systems of management and production technology in the leading seaweed industry overseas so that at an early stage, Indonesia can make a comparative study of the existing industrial facilities and even lead the industry in order to allow for the establishment of a branch (branch factory) in the country. Companies that have the ability to master the production technology and quality management system and international level as well as business support to the mastery of technology, with a record participation of Indonesian human resources remaining in the working process.

\section{(3) Business development}

The need to make efforts and encouragement / incentives in order to connect with kelp reliable entrepreneurs (entrepreneurs development), capital and funding, economic and fiscal incentives, 
technical assistance, commercialisation and market assistance and advisory business (business assistance) by the authorities (Ministry of Maritime Affairs and Fisheries, the Ministry of Industry, Seaweed Industry Association).

\section{(4) Attraction of foreign investment}

There is a need for the identification and promotion of company-processed seaweed that has potential in relation to domestic establishment, as well as the support of the Government's policy to stabilise the company's performance with regards to the valueadded products produced (high value added). It is as part of an effort to attract foreign investors and the establishment of internationally branded Indonesian seaweed products at the International level.

\section{(5) Investigation of critical mass}

The need to perform calculations or analysis related to cost and scaling strategies, patents and intellectual property products, as well as applied research with the accelerated study of marine biotechnology to produce products that meet international standards, the increase of investigation and negotiation capabilities so as to map and master the marketing network of seaweed products.

\section{(6) Social and environment improvement}

The need for the improvement of knowledge related to the production of seaweed (human resources development both culturally and society) as well as maintaining cluster development through the cultivation of seaweed, through regulations / policies issued by the Government, in particular the mapping of zoning in the industrialisation of seaweed.

\section{Conclusion}

Indonesia is one of the world's major suppliers of dried seaweeds. The seaweed cultivation in Indonesia is still using a simple method. The seaweed production can be improved by an advance should be identified in relation to marine plant research. Furthermore, Indonesia must have the capability for seaweed processing (not only producing the raw materials). The utilisation of seaweed in modern medicine, cosmetics, pharmacy, food, and industrial grades must be also increased by improving the capacity of human resources for the better cultivation technology of selected seaweeds and extraction techniques of bioactive substances.

\section{References}

Burkart, K., 2012. How to define the ,green economyee Available at: http://www.mnn.com/greentech/researchinnovations/blogs/how-do-youdefine-the-green-economy. [Accessed on 05 July 2012].

IEA (2010). World Energy Outlook 2010. International Energy Agency. Paris, France. $731 \mathrm{pp}$.

Lesperance, J. (2016) To mark World Oceans Day, we look at the origin and concept of the "blue economy". Connections. Virtual University for Small States of the Commonwealth (VUSSC). British Columbia, Canada.

O'Sullivan, A. and Sheffrin, S. M. (2003). Economics: Principles in Action. Pearson Prentice Hall, Upper Saddle River, New Jersey.

Pauli, G. (2010). The Blue Economy: 10 Years 100 Innovations 100 Million Jobs. Paradigm Publications. New Mexico, USA. 309 pp.

P2HP (2013) Export Statistics of Fisheries Product by Commodity, Province and Port of Export 2012. Center of Data, Statistics, and Information. Secretariat General, Ministry of Marine Affairs and Fisheries. Jakarta. 1329 pp.

UNDP (2017). UNDP Strategic Plan: 2014-2017. United Nations Development Programme. New York. USA. 62 pp.

United Nations (2015). The Millenium Development Goals Report 2015: Summary. New York, USA. 12 pp. 